\title{
Fixed point theorems for cyclic non-self single-valued almost contractions
}

\section{VAsile Berinde ${ }^{1,2}$ and Mihaela AnCuţa Petric ${ }^{1}$}

\section{ABSTRACT.}

Let $X$ be a Banach space, $A$ and $B$ two non-empty closed subsets of $X$ and let $T: A \cup B \rightarrow X$ be an operator. We define the notion of cyclic non-self almost contraction and we give a corresponding fixed point theorem.

Acknowledgements. The authors research was supported by the Grant PN-II-RU-TE2011-3-239 of the Romanian Ministry of Education and Research.

\section{REFERENCES}

[1] Alghamdi, M. A., Berinde, V. and Shahzad, N., Fixed points of multivalued non-self almost contractions, J. Appl. Math., 2013, Art. ID 621614, 6 pp.

[2] Berinde, V., On the approximation of fixed points of weak contractive mappings, Carpathian J. Math., 19 (2003), No. $1,7-22$

[3] Berinde, V., Approximating fixed points of weak $\varphi$-contractions using the Picard iteration, Fixed Point Theory, 4 (2003), No. 2, 131-142

[4] Berinde, V., Approximation fixed points of weak contractions using the Picard iteration, Nonlinear Analysis Forum, 9 (2004), No. 1, 43-53

[5] Berinde, V., Iterative Approximation of Fixed Points, 2nd Ed., Springer Verlag, Berlin Heildelberg New York, 2007

[6] Berinde, V. and Păcurar, M., Fixed point theorems for non-self single-valued almost contractions, Fixed Point Theory, 14 (2013), No. 2, 301-311

[7] Kannan, R., Some results on fixed points, Bull. Calcutta Math. Soc., 10 (1968), No. 1, 71-76

[8] Kirk, W. A., Srinivasan, P. S. and Veeramani P., Fixed Points For Mappings Satisfying Cyclical Contractive Conditions, Fixed Point Theory, vol. 4 (2003), No. 1, 79-89

[9] Păcurar, M. and Rus, I. A., Fixed point theorems for cyclic $\varphi$-contractions, Nonlinear Analysis: Theory, Methods and Applications, 72 (2010), No. 3-4, 1181-1187

[10] Petric, M. A. and Zlatanov, B., Best proximity points and fixed points for p-summing maps, Fixed Point Theory and Applications, 86 (2012), 145-154

[11] Petric, M. A., Best proximity point theorems for weak cyclic Kannan contractions, Filomat, 25 (2011), No. 1, $145-154$

[12] Petric, M. A., Some results concerning cyclical contractive mappings, General Mathematics, 18 (2010), No. 4, 213-226

[13] Petric, M. A., Some remarks concerning Ciric-Reich-Rus operators, Creative Math. And Inf., 18 (2010), No. 2, 188-193

[14] Petric, M. A.and Zlatanov, B., Fixed point theorems of Kannan type for cyclical contractive conditions, REMIA 2010 (Proceedings of the Anniversary International Conference, 10-12 December 2010), 187-194

[15] Petruşel, G., Cyclic representations and periodic points, Studia Univ. Babeş-Bolyai Math., 50 (2005), No. 3, $107-112$

[16] Rhoades, B. E., A comparison of various definitions of contractive mappings, Trans. Amer. Math. Soc.,226 (1977), $257-290$

[17] Rus, I. A., Generalized Contractions and Applications, Cluj University Press, Cluj-Napoca, 2001

Received: 23.03.2015; In revised form: 07.05.2015; Accepted: 10.05.2015

2010 Mathematics Subject Classification. 47H09, 47H10.

Key words and phrases. Fixed point, cyclic non-self operator, cyclic non-self almost contractions, Banach space.

Corresponding author: Petric Mihaela Ancuţa; petricmihaela@yahoo.com 
[18] Rus, I. A., Petruşel, A. and Petruşel, G., Fixed Point Theory, Cluj University Press, Cluj-Napoca, 2008

${ }^{1}$ Department of Mathematics and Computer Science

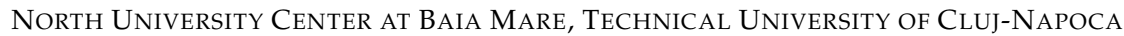

VICTORIEI 76, 430122 BAIA MARE ROMANIA

E-mail address: vberinde@ubm.ro; vasile_berinde@yahoo.com; petricmihaela@yahoo.com

2 Department of Mathematics and Statistics

King Fahd University of Petroleum and Minerals

DHAHRAN, SAUDI ARABIA

E-mail address: vasile.berinde@gmail.com 